\title{
MJN CLINICAL ASSOCIATION BETWEEN GESTATIONAL DIABETES MELLITUS AND QUALITY OF LIFE AMONG WOMEN
}

\author{
Ebtesam EL Sayed Shama ${ }^{1}$, Nadra Mohamed Ibrahiem $^{2}$, Amal Roshdi Ahmed ${ }^{3 *}$, Amany El-berdan ${ }^{4}$, \\ Eman El-Sherbeny ${ }^{5}$
}

\author{
${ }^{1}$ Department of Maternity, Obstetric and Gynecological Nursing, Faculty of Nursing-Port said University \\ Egypt \\ ${ }^{2}$ Maternity, Obstetrics and Gynecology Nursing, - Ismailia Technical Institute of Health Egypt \\ ${ }^{3}$ Department of Maternal \& Newborn Health Nursing, Faculty of Nursing, Beni-Suef University, Egypt \\ ${ }^{4}$ Medical surgical Nursing, Port-Said University, Egypt \\ ${ }^{5}$ Department of Community Health Nursing, Faculty of Nursing, Beni- Suef University, Egypt
}

*Corresponding Author's Email: mrahmed.abass@yahoo.com

\begin{abstract}
Introduction: Gestational Diabetes Mellitus rises the chance of health problems both risks development for the mom, and fetus. With adverse effects on psychological and medical well-being meaning a diminished in Quality of Life (QOL). Aim: To explore quality of life among women with gestational diabetes. Methods: A descriptive design was used for the study. The study was conducted at outpatient clinics of Suez Canal University Hospital. This study was conducted during June 2017 to December 2018. Convenience sample of two hundred pregnant women medically diagnosed with gestational diabetes were considered. Interview questionnaire sheet included five parts and QOL scale according to (Quality of life index diabetes version111). Results: A sum of 200 mothers diagnosed with GDM were studied, their age range between 20-42, with Mean \pm SD $29.7 \pm 5.8$ years, with gestational diabetes $(53 \%)$. The quality of life to be the best in the social/economic domain, psychological/ spiritual domain, family domain and slightly worse in the health and functioning domain $(66 \%, 64 \%, 48.0 \%$ and $32.0 \%$ respectively). There is highly significant difference between age, university education, living in urban area and knowledge. There is positive significant correlation between health and functioning domain, social economic domain, psychological spiritual domain and family domain with $p<0.001$. Conclusion: More than two thirds of the studied mothers were satisfied with both social/economic and psychological/spiritual domains. Majority of studied mothers have appropriate knowledge about management of hypoglycemia. More than three fourth of studied sample did not have knowledge about symptoms of GDM. Recommendations: Designing guideline and brochure must be distributed among women attending antenatal clinic about self-care to promote their health concerning gestational diabetes.
\end{abstract}

Keywords: Gestational Diabetes Mellitus, Quality of Life

\section{INTRODUCTION}

Gestational diabetes mellitus (GDM) is a known medical health problem of women during pregnancy which is a condition characterized by glucose intolerance of varying degrees of intensity, starting or being first diagnosed during pregnancy. It is defined as a glucose/carbohydrate intolerance with onset or first recognition during pregnancy which affects approximately $90 \%$ of women. Evidently GDM effects physical and psychological well-being which in turn effects Quality of Life by diminishing it QoL (Guglani, Shenoy \& Sandhu 2014; Lewk et al., 2012). With gravidity when there is a diagnosis of GDM it makes necessary for management of this problem with a team consisting of obstetrician, diabetes physician, a 
diabetes educator, dietician, midwife and pediatrician. GDM decreases QoL in all dimension including physical, functional, social and mental health (American Diabetes Association, 2017; Alptekin et al., 2016).

Moreover, QoL of gestational diabetic mothers may be affected by worries about their health and fetus, also a feeling of losing control of one's health. GDM affects virtually all aspects of a women's life such as deterioration in the women's physical and psychological wellbeing, a change in their lifestyle and its adaptation to the illness, as well as changes in physical, professional, and social activity along with diminished values. All of these aspects reflect the women's quality of life (WHO 2014; Sonino \& Fava 2012; Bień et al., 2015;RodriguezUrrutia et al., 2016

So, strategies are necessary to promote the health status by treating physical symptoms as well as instilling a positive psychological and mental state. Nurses are playing effective role in prevention, early detection, management of gestational diabetes and its complications through glycemic control and by increasing the quality of life of GDM women by education about treatment modality, screening highrisk group and providing health care. This is necessary for all gestational diabetic women, especially women at risk. The nurses' role is as a health care provider and also health educator for improving the quality of life (Danylivetal., 2015; Bechetal., 2016)

Aim: To explore the clinical association between gestational diabetes mellitus and quality of life among women.

Study question: Weather women's quality of life is affected by gestational diabetes?

\section{METHODOLOGY}

A descriptive study design was utilized on a convenience sample of two hundred pregnant women medically diagnosed with gestational diabetes at outpatient clinics of Suez Canal University Hospital. This study was conducted during the period from June 2017 to December 2018. Two types of tools were used for data collection Interview questionnaire sheet with five parts. First part was used to assess women general characteristics (questions numbers from 1 to 7 ) it included personal items such as, age, residence, educational levels, and occupation, place of receiving health care, mother's treatment costs and sufficient income to meet expenses of treatment. Second part was used to assess the mothers' health history (from questions number 8 to 18 ). Question number 8 was used to assess the time taken to diagnose gestational diabetes. Questions number 9 to 15 were used to assess mothers' medical surgical history. Question number 16 was used to assess surgical history and Question 17 and 18 were used to assess family history.

Third part was used to assess previous pregnancy history (Questions No. 19 to 21). Fourth part was used to assess the mothers' present pregnancy complains (Question No. 22). Fifth part was used to assess women's knowledge regarding gestational diabetes (Questions No. 23 to 32), women 'dietary habits (Question No. 33), mother's lifestyle (Question No. 34 and 35), Sleeping pattern (Questions No. 36) and personal hygiene (Questions No. 37 to 40). Knowledge scored as, Incorrect answer one, Correct answer two.

Second tool: QOL scale according to (Quality of life index diabetes version-111) developed from Calou, et al., (2014) and modified by the researcher. This tool was used to assess studied mothers' health/functioning, social/economic, psychological/ spiritual and family subscale, to assess mothers' quality of life with gestational diabetes. It includes 34 items (satisfaction part). Satisfaction scoring system was scored as the following: Unsatisfied scored as one, Uncertain scored as two, satisfied scored as three.

Pilot study was conducted on $10 \%$ of them "20" gestational diabetes women. Then according to the necessary modification of data collection plan and tools were done. Gestational diabetes mothers included on the pilot study was not involved in the sample size.

The researcher attended the previously mentioned study setting 3 days/ week from 8 am to $2 \mathrm{pm}$. The ethical research considerations in this study were included for each woman. They were separately interviewed to fill tools of data collection; they had the right to withdraw from the study at any time. The mothers were not harmed as Tools of data collection did not touch mothers' dignity or did not create any traditional and culture issues. All tools of data collection were burned after statistical analysis to maintain confidentiality. The study aim was explained to each participant through interviewing questionnaire; each interview took 15 minutes. Data collection 
continued until the sample size reached the predetermine number (200). All Administrative effort had been followed.

All statistical analyses were performed using SPSS for windows version 20.0 (SPSS, Chicago, IL). Mean \pm standard deviation (SD) for continuous data, while categorical data were expressed in number and percentage. Student's $t$ test or one-way analysis of variance (ANOVA test) respectively for variables with continuous data or chi-square test for variables containing categorical data. The Pearson correlation test was used to determine the correlation between two variables containing continuous data. Statistical significance was set at $p$-value $<0.05$,

\section{RESULTS}

About 200 women diagnosed GDM were studied, their age ranged between 20-42 years, among studied women with gestational diabetes mothers $(53 \%)$ their age ranged between 30 to $<40$ years, with Mean \pm SD $29.7 \pm 5.8,54 \%$ were living in urban area, $61 \%$ of them had secondary education, $79 \%$ were not working, and $55 \%$ income insufficient to meet their treatment. $42.5 \%$ of studied women had previous pregnancy history ( 3 to 4 times), among studied women only $48 \%$ had regular antenatal visit.

Table (1) displays that, $29 \%$ of studied women had previous abortion), (58.0\%) had previous cesarean section, $(27 \%)$ had bleeding and $(21.0 \%)$ had previously macrosomia.

Table 1: Frequency Distribution among Studied Sample According to History of Previous Pregnancies $(N=200)$

\begin{tabular}{|l|c|c|}
\hline \multicolumn{1}{|c|}{ Obstetric history } & No. & \% \\
\hline previous premature labor & 30 & 15.0 \\
\hline previous caesarean section & 116 & 58.0 \\
\hline previous f IUFD & 45 & 23.0 \\
\hline previous macrosomia & 42 & 21.0 \\
\hline $\begin{array}{l}\text { previous Congenital } \\
\text { abnormalities }\end{array}$ & 23 & 12.0 \\
\hline $\begin{array}{l}\text { previous Gestational } \\
\text { hypertension/toxemia of pregnancy }\end{array}$ & 36 & 18.0 \\
\hline Abortion & 58 & 29.0 \\
\hline Bleeding & 53 & 27.0 \\
\hline Gestational diabetes & 42 & 21.0 \\
\hline
\end{tabular}

*Statistical significant at $p$-value $<0.05 * *$ Highly statistical significant at $p$ value $<0.001$
Figure 1 shows that, studied sample quality of life to be the best in the social/economic domain, psychological/ spiritual domain, family domain and slightly worse in the health and functioning domain $(66 \%, 64 \%, 48 \%$ and $32 \%$ respectively).

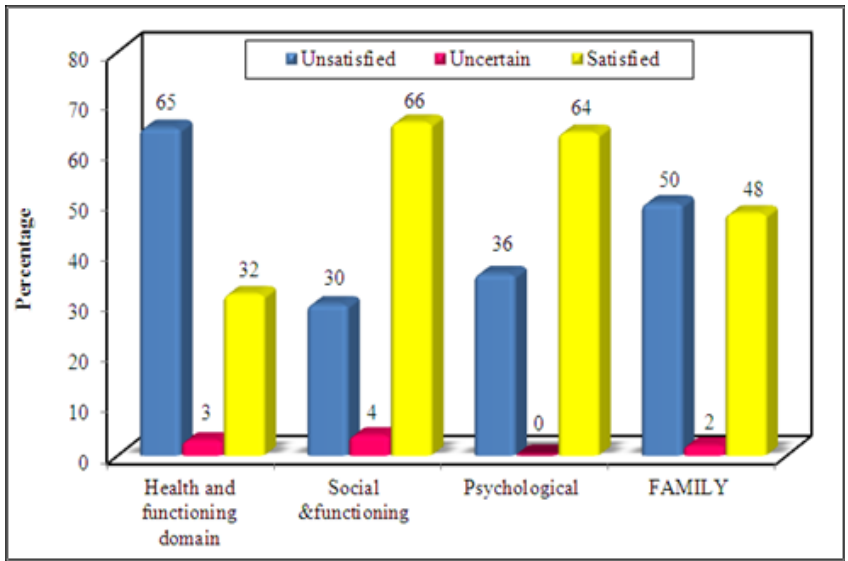

\section{Figure 1: Women Satisfaction}

Figure 2 studied sample satisfaction according to their gestational diabetes Total Quality of life

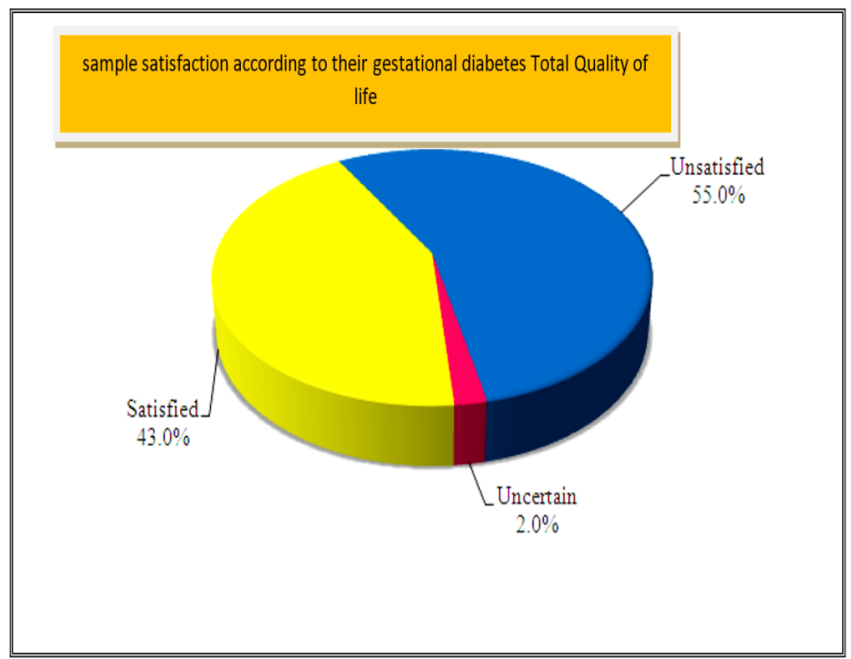

Figure 2: Sample satisfaction according to their
gestational diabetes Total Quality of life

Table 2 illustrate that, gestational diabetes women with age group from 30 to $<40$ years were significantly satisfied living in urban area, had university education, there was association with non-working QOL index satisfaction. However, there was no association between the residence, occupation, and income. 
Table 2: The Association Between Sample General Characteristics with The Total QOL Index Satisfaction

\begin{tabular}{|c|c|c|c|c|c|c|c|c|}
\hline & \multicolumn{6}{|c|}{ Total QOL index satisfaction } & & \\
\hline & \multicolumn{2}{|c|}{ Unsatisfied (110) } & \multicolumn{2}{|c|}{ Uncertain (4) } & \multicolumn{2}{|c|}{ Satisfied (86) } & \multicolumn{2}{|c|}{ Chi square test } \\
\hline & No. & $\%$ & No. & $\%$ & No. & $\%$ & $X^{2}$ & $P$ \\
\hline \multicolumn{9}{|l|}{ Age by year } \\
\hline $20<30$ & 13 & $12.0 \%$ & 2 & $50 \%$ & 36 & $42.0 \%$ & & \\
\hline $30<40$ & 68 & $62.0 \%$ & 0 & $0 \%$ & 38 & $44.1 \%$ & & \\
\hline$\geq 40$ & 29 & $26.0 \%$ & 2 & $50 \%$ & 12 & $13.9 \%$ & 26.716 & $<0.001^{* *}$ \\
\hline \multicolumn{9}{|l|}{ Residence } \\
\hline Rural & 54 & $49.6 \%$ & 4 & $100 \%$ & 33 & $38.3 \%$ & & \\
\hline Urban & 56 & $51.0 \%$ & 0 & $0 \%$ & 53 & $61.4 \%$ & 5.789 & 0.091 \\
\hline \multicolumn{9}{|l|}{ Educational status } \\
\hline Cannot Read \& Write & 9 & $8.1 \%$ & 0 & $0 \%$ & 17 & $20.0 \%$ & & \\
\hline Basic & 7 & $6.3 \%$ & 0 & $0 \%$ & 17 & $20.0 \%$ & & \\
\hline Secondary & 92 & $83.6 \%$ & 4 & $100 \%$ & 26 & $30.0 \%$ & & \\
\hline University \& above & 2 & $2.0 \%$ & 0 & $0 \%$ & 26 & $30.0 \%$ & 66.157 & $<0.001 * *$ \\
\hline \multicolumn{9}{|l|}{ Occupational status } \\
\hline Working & 13 & $12.0 \%$ & 0 & $0 \%$ & 29 & $24.0 \%$ & & \\
\hline Not working & 97 & $88.0 \%$ & 4 & $100 \%$ & 57 & $66.0 \%$ & 5.739 & 0.060 \\
\hline \multicolumn{9}{|c|}{ Income sufficient for treatment } \\
\hline Yes & 44 & $40 \%$ & 4 & $100 \%$ & 43 & $50.0 \%$ & & \\
\hline No & 66 & $60 \%$ & 0 & $0 \%$ & 43 & $50.0 \%$ & 5.253 & 0.119 \\
\hline
\end{tabular}

*Statistical significant at p-value $<0.05 *$ Highly statistical significant at p-value $<0.001$

Table 3 reveals that there is association between women diagnosed in $3^{\text {rd }}$ trimester were more satisfied $(69.0 \%$; $p<0.001)$, taken insulin (68.0\%) without family history of diabetes $(60.0 \%, p<0.001)$ and QOL satisfaction index.

Table 3: Relation Between Medical History of Studied Sample with Their Total QOL Index Satisfaction

\begin{tabular}{|c|c|c|c|c|c|c|c|c|}
\hline & \multicolumn{6}{|c|}{ Total QOL index satisfaction } & & \\
\hline & \multicolumn{2}{|c|}{ Unsatisfied (110) } & \multicolumn{2}{|c|}{ Uncertain (4) } & \multicolumn{2}{|c|}{ Satisfied (86) } & \multicolumn{2}{|c|}{ Significant test } \\
\hline & No. & $\%$ & No. & $\%$ & No. & $\%$ & $\overline{X^{2}}$ & $P$ \\
\hline \multicolumn{7}{|c|}{ Time of GD diagnoses } & \multirow{3}{*}{21.446} & \multirow{3}{*}{$<0.001 * *$} \\
\hline $2^{\text {nd }}$ trimester & 70 & 63.8 & 2 & 50.0 & 26 & 30.1 & & \\
\hline $3^{\text {rd }}$ trimester & 68 & 36.2 & 2 & 50.0 & 60 & 69.9 & & \\
\hline \multicolumn{9}{|l|}{ Take insulin } \\
\hline Yes $(n=164)$ & 102 & 93.0 & 4 & 100.0 & 58 & 68.0 & \multirow{2}{*}{22.526} & \multirow{2}{*}{$<0.001 * *$} \\
\hline No $(n=36)$ & 8 & 7.0 & 0 & 0.0 & 28 & 32.0 & & \\
\hline \multicolumn{9}{|c|}{ +ve family history of DM } \\
\hline Yes & 88 & 80.0 & 4 & 100.0 & 34 & 40.0 & \multirow{2}{*}{34.951} & \multirow{2}{*}{$<0.001 * *$} \\
\hline No & 12 & 20.0 & 0 & 0.0 & 52 & 60.0 & & \\
\hline
\end{tabular}

**Highly statistical significant at p-value $<0.001$ 
Table 4 reveals that there is highly significant difference between age, university education, living in urban area and knowledge.

Table 4: The Correlation between General Characteristics and The Total Knowledge Score of The Studied Women

\begin{tabular}{|c|c|c|c|}
\hline \multirow[t]{2}{*}{ General characteristics } & \multirow{2}{*}{$\begin{array}{c}\text { Total knowledge score } \\
\text { Mean } \pm \text { SD }\end{array}$} & \multicolumn{2}{|c|}{ ANOVA test } \\
\hline & & $F$ & $\boldsymbol{P}$ \\
\hline \multicolumn{4}{|l|}{ Age by year } \\
\hline $20-<30$ & $5.6 \pm 1.8$ & & \\
\hline $30-<40$ & $6.8 \pm 1.9$ & & \\
\hline$\geq 40$ & $6.5 \pm 1.7$ & 7.253 & $<0.001 * *$ \\
\hline \multicolumn{4}{|l|}{ Residence } \\
\hline Rural & $6.1 \pm 1.6$ & & \\
\hline Urban & $6.5 \pm 2.1$ & 4.087 & $0.038 *$ \\
\hline \multicolumn{4}{|l|}{ Educational status } \\
\hline Cannot Read \& Write & $5.1 \pm 2$ & & \\
\hline basic & $5.6 \pm 1.6$ & & \\
\hline Secondary & $6.5 \pm 2.1$ & & \\
\hline University & $6.9 \pm 1.7$ & 27.005 & $<0.001 * *$ \\
\hline \multicolumn{4}{|l|}{ Occupational status } \\
\hline Working & $6.3 \pm 1.3$ & & \\
\hline Not working & $6.4 \pm 2.8$ & 0.305 & 0.586 \\
\hline \multicolumn{4}{|l|}{ Income sufficient for treatment } \\
\hline Yes & $6.4 \pm 1.9$ & & \\
\hline No & $6.2 \pm 1.8$ & 0.503 & 0.623 \\
\hline
\end{tabular}

*Statistical significant at p-value $<0.05 * *$ Highly statistical significant at p-value $<0.001$

Table 5 shows that, women were satisfied with management of gestational disease, management of hypoglycemia, dangerous fetal symptoms, $(85.0 \%, 100 \%$ and $50 \%$ respectively). There were no association between performance of physical activity, symptoms and management of GDM and total QOL index satisfaction.

Table 5: The Association Between Studied Sample Knowledge with their Total Satisfaction Scores

\begin{tabular}{|c|c|c|c|c|c|c|c|c|}
\hline & \multicolumn{6}{|c|}{ Total QOL index satisfaction } & & \\
\hline & \multicolumn{2}{|c|}{ Unsatisfied } & \multicolumn{2}{|c|}{ Uncertain } & \multicolumn{2}{|c|}{ Satisfied } & \multicolumn{2}{|c|}{ Significant test } \\
\hline & No. & $\%$ & No. & $\%$ & No. & $\%$ & $X^{2}$ & $\boldsymbol{P}$ \\
\hline \multicolumn{9}{|c|}{ Symptoms of gestational diabetes } \\
\hline Incorrect & 86 & 78.0 & 4 & 100.0 & 63 & 73.0 & \multirow{2}{*}{0.586} & \multirow{2}{*}{0.746} \\
\hline Correct & 24 & 22.0 & 0 & 0.0 & 23 & 27.0 & & \\
\hline
\end{tabular}




\begin{tabular}{|c|c|c|c|c|c|c|c|c|}
\hline \multicolumn{9}{|c|}{ Management of gestational diabetes } \\
\hline Incorrect & 33 & 30.0 & 4 & 100.0 & 43 & 50.0 & \multirow{2}{*}{4.320} & \multirow{2}{*}{0.115} \\
\hline Correct & 77 & 70.0 & 0 & 0.0 & 43 & 50.0 & & \\
\hline \multicolumn{9}{|c|}{ Effect of gestational diabetes on mother } \\
\hline Incorrect & 25 & 23.0 & 4 & 100.0 & 48 & 56.0 & \multirow{2}{*}{11.818} & \multirow{2}{*}{$0.003 * *$} \\
\hline Correct & 85 & 77.0 & 0 & 0.0 & 38 & 44.0 & & \\
\hline \multicolumn{9}{|c|}{ Effect of gestational diabetes on fetus } \\
\hline Incorrect & 23 & 21.0 & 0 & 0.0 & 46 & 53.0 & \multirow{2}{*}{10.145} & \multirow{2}{*}{$0.006 * *$} \\
\hline Correct & 87 & 79.0 & 4 & 100.0 & 40 & 47.0 & & \\
\hline \multicolumn{9}{|c|}{ Methods of protection from gestational diabetes } \\
\hline Incorrect & 51 & 46.0 & 4 & 100.0 & 60 & 70.0 & \multirow{2}{*}{5.836} & \multirow{2}{*}{0.054} \\
\hline Correct & 59 & 54.0 & 0 & 0.0 & 26 & 30.0 & & \\
\hline \multicolumn{9}{|c|}{ Management of hypoglycemia } \\
\hline Incorrect & 4 & 4.0 & 0 & 0.0 & 13 & 15.0 & \multirow{2}{*}{1.741} & \multirow{2}{*}{0.419} \\
\hline Correct & 106 & 96.0 & 4 & 100.0 & 73 & 85.0 & & \\
\hline \multicolumn{9}{|c|}{ Motherdangeroussymptoms signs } \\
\hline Incorrect & 36 & 33.0 & 4 & 100.0 & 10 & 12.0 & \multirow{2}{*}{8.036} & \multirow{2}{*}{$0.018 *$} \\
\hline Correct & 74 & 67.0 & 0 & 0.0 & 76 & 88.0 & & \\
\hline \multicolumn{9}{|c|}{ Fetal dangeroussymptoms } \\
\hline Incorrect & 106 & 96.0 & 4 & 0.0 & 0 & 0.0 & \multirow{2}{*}{3.436} & \multirow{2}{*}{0.296} \\
\hline Correct & 4 & 4.0 & 0 & 100.0 & 86 & 100.0 & & \\
\hline \multicolumn{9}{|c|}{ Measure blood glucose at home } \\
\hline Incorrect & 33 & 30.0 & 0 & 0.0 & 43 & 50.0 & \multirow{2}{*}{4.320} & \multirow{2}{*}{0.115} \\
\hline Correct & 77 & 70.0 & 4 & 100.0 & 43 & 50.0 & & \\
\hline \multicolumn{9}{|c|}{ Frequency of measuring blood glucose at home } \\
\hline Incorrect & 55 & 50.0 & 4 & 100.0 & 46 & 53.0 & 4.024 & 0.599 \\
\hline
\end{tabular}

*Statistical significant at $p$-value $<0.05 * *$ Highly statistical significant at $p$-value $<0.001$ 
Table 6 shows that, there is a highly significant difference of satisfaction and knowledge of time and direction of performance along with perineal care.

Table 6: The Relation Between Studied Sample Knowledge Regarding Personal Hygiene with the Total QOL Index Satisfaction.

\begin{tabular}{|c|c|c|c|c|c|c|c|c|}
\hline & \multicolumn{6}{|c|}{ Total QOL index satisfaction } & & \\
\hline & \multicolumn{2}{|c|}{ Unsatisfied } & \multicolumn{2}{|c|}{ Uncertain } & \multicolumn{2}{|c|}{ Satisfied } & \multicolumn{2}{|c|}{ Significant test } \\
\hline & No. & $\%$ & No. & $\%$ & No. & $\%$ & $X^{2}$ & $\boldsymbol{P}$ \\
\hline \multicolumn{9}{|c|}{ Taking shower daily } \\
\hline Incorrect & 87 & 82.9 & 2 & 100.0 & 39 & 41.9 & \multirow[b]{2}{*}{36.982} & \multirow[b]{2}{*}{$<0.001 * *$} \\
\hline Correct & 18 & 17.1 & 0 & 0.0 & 54 & 58.1 & & \\
\hline \multicolumn{9}{|c|}{ Skin and feet care } \\
\hline Incorrect & 0 & 0.0 & 0 & 0.0 & 0 & 0.0 & \multirow[b]{2}{*}{0.0} & \multirow[b]{2}{*}{1.000} \\
\hline Correct & 105 & 100.0 & 2 & 100.0 & 93 & 100.0 & & \\
\hline \multicolumn{9}{|c|}{ Benefit of perineal care } \\
\hline Incorrect & 13 & 12.4 & 0 & 0.0 & 47 & 50.5 & \multirow[b]{2}{*}{35.058} & \multirow[b]{2}{*}{$<0.001 * *$} \\
\hline Correct & 92 & 87.6 & 2 & 100.0 & 46 & 49.5 & & \\
\hline \multicolumn{9}{|c|}{ Direction of perineal care } \\
\hline Incorrect & 85 & 81.0 & 2 & 100.0 & 52 & 55.9 & \multirow[b]{2}{*}{15.473} & \multirow[b]{2}{*}{$<0.001 * *$} \\
\hline Correct & 20 & 19.0 & 0 & 0.0 & 41 & 44.1 & & \\
\hline \multicolumn{9}{|c|}{ Signs and symptoms of vaginal infections } \\
\hline Incorrect & 29 & 27.6 & 0 & 0.0 & 33 & 35.5 & \multirow[b]{2}{*}{2.334} & \multirow[b]{2}{*}{0.311} \\
\hline Correct & 76 & 72.4 & 2 & 100.0 & 60 & 64.5 & & \\
\hline
\end{tabular}

**Highly statistical significant at p-value $<0.001$

Table 7 shows that there was association with complaining from dry mouth, feel thirsty, frequently, urination, recurrent GU infections, intense hunger and total QOL satisfaction, but there were no association between dry mouth and total QOL satisfaction.

Table 7: Relation Between Current Pregnancy Complains of Studied Sample with Their Total QOL Index Satisfaction

\begin{tabular}{|c|c|c|c|c|c|c|c|c|}
\hline \multirow[t]{3}{*}{ Complains } & \multicolumn{6}{|c|}{ Total QOL index satisfaction } & & \\
\hline & \multicolumn{2}{|c|}{ Unsatisfied } & \multicolumn{2}{|c|}{ Uncertain } & \multicolumn{2}{|c|}{ Satisfied } & \multicolumn{2}{|c|}{ Significant test } \\
\hline & No.110 & $\%$ & No.4 & $\%$ & No.86 & $\%$ & $X^{2}$ & $\boldsymbol{P}$ \\
\hline \multicolumn{9}{|c|}{ Dry mouth feel thirst } \\
\hline Yes & 110 & 100.0 & 4 & 100.0 & 81 & 94.0 & \multirow{2}{*}{8.890} & \multirow{2}{*}{$0.010^{*}$} \\
\hline No & 0 & 0.0 & 0 & 0.0 & 5 & 6.0 & & \\
\hline \multicolumn{9}{|c|}{ Frequent urination } \\
\hline Yes & 109 & 99.0 & 4 & 100.0 & 83 & 97.0 & \multirow{2}{*}{9.230} & \multirow{2}{*}{$0.010^{*}$} \\
\hline No & 1 & 1.0 & 0 & 0.0 & 3 & 3.0 & & \\
\hline \multicolumn{9}{|c|}{ Fatigue and loss of concentration } \\
\hline Yes & 108 & 98.1 & 4 & 100.0 & 59 & 68.8 & \multirow{2}{*}{31.648} & \multirow{2}{*}{$<0.001 * *$} \\
\hline No & 2 & 1.9 & 0 & 0.0 & 27 & 31.2 & & \\
\hline \multicolumn{9}{|c|}{ Recurrent GU infections } \\
\hline Yes & 106 & 96.0 & 4 & 100 & 80 & 93.0 & \multirow{2}{*}{6.745} & \multirow{2}{*}{$0.034 *$} \\
\hline No & 4 & 4.0 & 0 & 0.0 & 6 & 7.0 & & \\
\hline \multicolumn{9}{|c|}{ Blurred vision } \\
\hline Yes & 103 & 94.0 & 4 & 100.0 & 65 & 73.0 & \multirow{2}{*}{21.212} & \multirow{2}{*}{$<0.001 * *$} \\
\hline No & 3 & 6.0 & 0 & 0.0 & 23 & 27.0 & & \\
\hline \multicolumn{9}{|c|}{ GIT problems } \\
\hline Yes & 107 & 97.0 & 4 & 100.0 & 80 & 93.0 & \multirow{2}{*}{8.464} & \multirow{2}{*}{$0.015 *$} \\
\hline No & 3 & 3.0 & 0 & 0.0 & 6 & 7.0 & & \\
\hline \multicolumn{9}{|c|}{ Mood changes and Nervousness } \\
\hline Yes & 102 & 93.0 & 4 & 100.0 & 61 & 71.0 & \multirow{2}{*}{32.434} & \multirow{2}{*}{$<0.001 * *$} \\
\hline No & 8 & 7.0 & 0 & 0.0 & 25 & 29.0 & & \\
\hline
\end{tabular}


Table 8 shows that positive significant correlation between health and functioning domain, social economic domain, psychological spiritual domain and family domain (significant correlation $p<0.001$ ).

Table 8: Association of Total Score of Satisfaction and Quality of Life Domains of The Studied Women

\begin{tabular}{|c|c|c|c|c|c|c|c|c|}
\hline & \multicolumn{6}{|c|}{ QOL index domains } & & \\
\hline & \multicolumn{2}{|c|}{ Health / functioning } & \multicolumn{2}{|c|}{ Social / economic } & \multicolumn{2}{|c|}{$\begin{array}{c}\text { Psychological / } \\
\text { spiritual }\end{array}$} & \multicolumn{2}{|c|}{ Family } \\
\hline & $r$ & $P$ & $r$ & $p$ & $r$ & $p$ & $\boldsymbol{R}$ & $\boldsymbol{P}$ \\
\hline Health/ functioning & & & 0.500 & $<0.001^{* *}$ & 0.669 & $<0.001^{* *}$ & 0.690 & $<0.001 * *$ \\
\hline Social/ economic & 0.500 & $<0.001^{* *}$ & & & 0.438 & $<0.001^{* *}$ & 0.603 & $<0.001 * *$ \\
\hline $\begin{array}{l}\text { Psychological/ } \\
\text { spiritual }\end{array}$ & 0.669 & $<0.001 * *$ & 0.438 & $<0.001 * *$ & & & 0.701 & $<0.001 * *$ \\
\hline Family & 0.690 & $<0.001^{* *}$ & 0.603 & $<0.001 * *$ & 0.701 & $<0.001 * *$ & & \\
\hline Total score & 0.922 & $<0.001 * *$ & 0.692 & $<0.001 * *$ & 0.838 & $<0.001 * *$ & 0.854 & $<0.001 * *$ \\
\hline
\end{tabular}

*Statistical significant at p-value $<0.05 * *$ Highly statistical significant at $p$-value $<0.001$

\section{DISCUSSION}

The aim of the present work was to study quality of life among mothers with gestational diabetes; this aim of the present study was significantly achieved through the present research question "Does gestational diabetes affects mother's quality of life?"

Concerning the studied samples' satisfaction with their gestational diabetes the result revealed that, majority of women were unsatisfied with health and functioning subscale. This finding was in accordance with Dalfrà et al., (2012) who evaluated quality of life among 245 pregnant with diabetes, among them 30 women were with type 1 diabetes mellitus (T1DM), 176 women with gestational diabetes (GDM) and 39 women chosen as control group; they were followed up at Italian diabetes clinics. It was reported that GDM women had worse physical well-being.

These study findings were disagreed with Manjunath et al., (2014) who studied quality of life among patients with type 2 diabetes in diabetic clinic at Rural South India in Tamil Nadu. About 50 patients were checked each week. The patients who were attending this clinic once in two to three months found that, less than two thirds of patients had good physical QOL.

Another study by Ozder et al., (2014) assessed the quality of life and degree of satisfaction with the treatment of 180 adult patients with type 2 diabetes mellitus (T2DM) in primary health care at Turkey, they reported that diabetes had the least impact on the physical activities.

Also the result of the present study revealed that, two third studied samples was satisfied with social economic domain. Previous study finding was in the same line with Bien et al., (2016) who analyzed the factors affecting the quality of life (QOL) and the illness acceptance of diabetic pregnant women. Among 114 pregnant women with diabetes reported that quality of life to be the best in the social domain.

Meanwhile these study findings were opposite with Manjunath et al., (2014) who found that, less than two thirds of patients had poor score in social domain. That may be related to different culture and educational level of the target population in the two studies.

The present study finding showed that, about two thirds of mothers had satisfaction with psychological/ spiritual domain. the previous study finding was in the same line with Bien et al., mentioned that, quality of life to be the best in the psychological domain.

Meanwhile the previous study finding was on converse with Dalfrà et al., (2012) who evaluated quality of life among 245 pregnant women with diabetes followed up at Italian diabetes clinics; they reported that, the studied patients had lower mental component scores.

Concerning general characteristics of the studied sample with the total QOL index satisfaction the result of the present study revealed that, the majority of mothers aged less than 40 years had more satisfaction. The previous study finding was with the same line with 
Al-Maskari et al., (2011) who found relationship between the presence of affective disturbance, poor glycemic control and complications in people with type2 diabetes of health-related quality of life. It was reported that patients' QOL score was higher among patients aged less than 40 years. This is because younger patient nowadays utilized and engage with technology more to understanding what is needed for manage their disease.

Meanwhile, the previous study finding was in opposition with Danyliv et al., (2015) who examined HRQOL in a group of women who had GDM in the index pregnancy 2 to 5 years previously and compared it to a group of women with normal glucose tolerance among 243 patients and mentioned that no association was found between HRQOL and age.

Also the present study finding was on converse with Porojan et al., (2012) who analyzed the quality of life in a group of diabetic patients without major complications among 50 patients who were attending the Department of Internal Medicine, Cluj-Napoca, Romania, reported that there were no statistical significant correlations found between QOL scales and age.

The result of the current study indicated that, there was highly significant association between studied sample's income and their QOL index satisfaction. The previous study finding disagreed with Ozder et al., (2014) who assessed the quality of life and degree of satisfaction with the treatment of 180 patients with type 2 diabetes mellitus (T2DM) at primary health care in Turkey. They reported that, patients' income showed no significant association with their quality of life domains. This deference was related to different society and culture for both studies.

Concerning the association of studied sample knowledge and total satisfaction score, the present study revealed that there was significant association between gestational diabetes knowledge and blood glucose testing. The previous study finding was in the same line with Kueh et al., (2015) who examined a model describing the relationship between diabetes knowledge, attitudes, self-management, and QOL of people with T2DM among 291 Australian patients and found that, there was significant relationship between diabetes knowledge and blood glucose testing. This similarity related to education of women with gestational diabetes about the effects of disease and awareness to manage their diabetes to minimize its impact.
Otherwise the present study found no association between knowledge and quality of life satisfaction. The previous study finding was in the same line with Kueh et al., (2015) who reported that knowledge did not directly affect diabetic patients' QOL but knowledge affected satisfaction of diabetic patients' QOL indirectly through patients'attitudes.

According relation of studied sample knowledge regarding personal hygiene with the total QOL index satisfaction, the present study revealed that there was highly significant association between satisfaction total score and knowledge of performing perineal care.

Regarding association of general characteristics of studied mothers with their knowledge score; the present study revealed that mothers who were living in urban area had more knowledge about gestational diabetes; also, the results revealed that, there was significant association in knowledge and education. The previous study finding was in the same line with Nisar et al., (2008) who assessed knowledge about diabetes mellitus and assessed the risk of behavioral and the environmental factors among non-diabetics. The results revealed that, people living in urban area were found more knowledgeable about diabetes mellitus; there was statistically significant difference in knowledge regarding diabetes mellitus observed between the educated people.

The result of the current study showed that, knowledge was better between age group 30 to below 40 , also it showed a highly significant difference between age and knowledge and highly significant difference between education and knowledge. This finding was in the same line with Jabbar et al., (2001) who determined the standard of knowledge among 230 people with diabetes in three diabetes centers in the city of Karachi, Pakistan and found that, knowledge was better among younger patients. Also, higher educational index had a higher standard of knowledge and there was significant correlation. This similarity may be due to women with educational background had correct knowledge than mothers with limited educational background.

Regarding medical history of studied women association with the total QOL index satisfaction; the present study showed that, more than two thirds of mothers were satisfied with insulin treatment and there was highly statistically significant association between insulin treatment and quality of life satisfaction. 
The previous study finding was on converse with Porojan, Poanta \& Dumitrascu, (2012) who analyzed that the quality of life in a group of diabetic patients reported that there was no statistically significant correlation between QOL scales and insulin treatment.

Also the previous study finding disagreed with Redekop et al., (2002) who estimated the health-related quality of life (HRQOL) and treatment satisfaction for patients with type 2 diabetes among 1,348 type 2 diabetes patients in the Netherlands, they found that patients who were treated with insulin reported a lower quality of life.

The present study revealed that, approximately one third of the study subjects had comorbidities and there was no association between comorbidities and mothers' quality of life satisfaction. The previous study finding was in the same line with Ozder, Sekeroglu \& Eker (2014) who assessed the quality of life and degree of satisfaction with the treatment of patients with type 2 diabetes mellitus (T2DM) among 180 patients in primary health care in Turkey. They reported that more than half of mothers had comorbidities; and there was no association between comorbidities and mothers' quality of life.

Likewise, the previous study finding was in line with Redekop et al., (2002) who estimated the healthrelated quality of life (HRQOL) and treatment satisfaction for patients with type 2 diabetes revealed that, presence of comorbidities was associated with a lower quality of life.

Regarding association of general characteristics of studied sample current pregnancy complain with their total QOL index satisfaction. The present study revealed that pregnancy complications were found to be statistically associated with quality of life index satisfaction. The previous study finding was line with Ozder, Sekeroglu \& Eker (2014) who assessed the quality of life and degree of satisfaction with the treatment of patients with type 2 diabetes mellitus reported that the pregnancy complications was found to be statistically associated with quality of life.

Meanwhile the previous study finding disagree with
Sopian \& Shahabudin, (2016) who studied the relation of yeast infection and diabetes mellitus among pregnant Mother in Malaysia. Among 740 pregnant ladies 370 were diabetic and 370 were non-diabetic cases. No association between diabetes and the frequency of occurrence of vaginal yeast infection was found.

Concerning correlation of studied sample satisfaction total score and quality of life domains the present study revealed that, there was positive correlation between all domains. This finding was in line with Danyliv et al., (2015) who examined HRQOL in a group of women who had GDM in the index pregnancy for 2 to 5 years previously and compared it to a group of women with normal glucose tolerance among found that there was positive correlation found between QOL domains.

\section{CONCLUSION}

More than two thirds of the studied women were more satisfied with both in psychological/ spiritual domains, social/economic and GDM affects studied women health and functioning domains. Majority of studied women have correct knowledge about management GDM.

\section{Recommendation}

- Developing awareness raising program to enhance women knowledge regarding promotion of their health in relation to gestational diabetes.

- Designing guideline and brochure must be distributed among women attending antenatal clinic about self-care to promote their health concerning gestational diabetes.

- Further study on the effect of advanced practices care mixed up with pharmacological aspect were based on information technologies on Quality of Life.

\section{Conflict of Interests}

The authors declare that they have no conflict of interest.

\section{ACKNOWLEDGEMENT}

The authors are thankful to the institutional authority for completion of the work.

\section{REFERENCES}

Al-Maskari, M.Y., Al-Shookri, A.O., Al-Adawi, S.H. \& Lin, K.G. (2011). Assessment of quality of life in patients with type 2 diabetes mellitus in Oman. Saudi Medical Journal, 32(12), pp 1285-1290. 
Alptekin, H., Çizmecioğlu, A., Işı1k, H., Cengiz, T., Yildiz, M. \& Iyisoy, M. (2016). Predicting gestational diabetes mellitus during the first trimester using anthropometric measurements and HOMA-IR. Journal of Endocrinological Investigation, 39(5), pp 577-583.

American Diabetes Association (2017). Classification and diagnosis of diabetes. Diabetes Care, 40(Supplement 1), pp S11-S24.

Bech, P., Carrozzino, D., Austin, S., Møller, S.B. \& Vassend, O. (2016). Measuring euthymia within the Neuroticism Scale from the NEO Personality Inventory: a Mokken analysis of the Norwegian general population study for scalability. Journal of Affective Disorders, 193, pp 99-102.

Bień, A., Rzońca, E., Kańczugowska, A. \& Iwanowicz-Palus, G. (2016). Factors affecting the quality of life and the illness acceptance of pregnant women with diabetes. International Journal of Environmental Research and Public Health, , 13(1), p 68.

Calou, C.G.P., Pinheiro, A.K.B., Castro, R.C.M.B., Oliveira, M.F.D., Aquino, P.D.S. \& Antezana, F.J. (2014). Health related quality of life of pregnant women and associated factors: An integrative review.

Dalfrà, M. G., Nicolucci, A., Bisson, T., Bonsembiante, B. \& Lapolla, A. (2012). Quality of life in pregnancy and postpartum: a study in diabetic patients. Quality of Life Research, 21(2), pp 291-298.

Danyliv, A., Gillespie, P., O'Neill, C., Noctor, E., O'Dea, A., Tierney, M., McGuire, B.E., Glynn, L.G. \& Dunne, F. P. (2015). Health related quality of life two to five years after gestational diabetes mellitus: cross-sectional comparative study in the ATLANTIC DIP cohort. BMC pregnancy and childbirth, 15(1), 274.

Guglani, R., Shenoy, S. \& Sandhu, J.S. (2014). Effect of progressive pedometer based walking intervention on quality of life and general well being among patients with type 2 diabetes. Journal of Diabetes \& Metabolic Disorders, 13(1), p 110.

Jabbar, A., Contractor, Z., Ebrahim, M. \& Mahmood, K. (2001). Standard of knowledge about their disease among patients with diabetes in Karachi, Pakistan. Journal of Pakistan Medical Association, 51(6), pp 216.

Kueh, Y.C., Morris, T., Borkoles, E. \& Shee, H. (2015). Modelling of diabetes knowledge, attitudes, selfmanagement, and quality of life: a cross-sectional study with an Australian sample. Health and quality of life outcomes, 13(1), p 129.

Lewko, J., Kochanowicz, J., Zarzycki, W., Mariak, Z., Górska, M. \& Krajewska-Kulak, E. (2012). Poor hand function in diabetics: Its causes and effects on the quality of life. Saudi Medical Journal, 33(4), pp 429-35

Manjunath, K., Christopher, P., Gopichandran, V., Rakesh, P.S., George, K. \& Prasad, J.H. (2014). Quality of life of a patient with type 2 diabetes: A cross-sectional study in Rural South India. Journal of Family Medicine and Primary Care, 3(4), p 396.

Nisar, N., Khan, I., Qadri, M. \& Sher, S. (2008). Knowledge and risk assessment of diabetes mellitus at primary care level: a preventive approach required combating the disease in a developing country. Pakistan Journal of Medical Sciences, 24(5), pp 667-672.

Ozder, A., Sekeroglu, M. \& Eker, H. (2014). Quality of life and satisfaction with treatment in subjects with type 2 diabetes: results from primary health care in Turkey. International Journal of clinical and experimental medicine, $7(12), \mathrm{p} 5715$.

Porojan, M., Poanta, L. \& Dumitrascu, D.L. (2012). Assessing health related quality of life in diabetic patients. Romanian Journal of Internal Medicine, 50(1), pp 27-31. 
Redekop, W., Koopmanschap, M., Stolk, R., Rutten, G., Wolffenbuttel, B.H. \& Niessen, L. (2002). Health-related quality of life and treatment satisfaction in Dutch patients with type 2 diabetes. Diabetes Care, 25(3), pp 458-463.

Rodriguez-Urrutia, A., Eiroa-Orosa, F., Accarino, A., Malagelada, C. \& Azpiroz, F. (2016). Incongruence between clinicians' assessment and self-reported functioning is related with psychopathology among patients diagnosed with gastrointestinal disorders. Psychotherapy and Psychosomatics, 85(4), pp 244-245.

Sonino, N. \& Fava, G.A. (2012). Improving the concept of recovery in endocrine disease by consideration of psychosocial issues. The Journal of Clinical Endocrinology \& Metabolism, 97(8), pp 2614-2616.

Sopian, I, Sa'adiah Shahabudin, M., Lung, L. \& Sandai, D. (2016). Yeast infection and diabetes mellitus among pregnant mother in Malaysia. The Malaysian journal of medical sciences: MJMS, 23(1), 27.

World Health Organization (WHO) (2014). Basic documents. Geneva. World Health Organization, pp 1. 